Article

\title{
Evolution of the microstructure and mechanical properties of a Ti35Nb2Sn alloy post-processed by Hot Isostatic Pressing for biomedical applications
}

\author{
Joan Lario ${ }^{1 *}$, Ángel Vicente ${ }^{1}$ and Vicente Amigó ${ }^{1}$ \\ ${ }^{1}$ Universitat Politècnica de València, Camino de Vera s/n, 5E Building, 46022 Valencia, Spain; joalafe@upv.es \\ * Correspondence: joalafe@upv.es
}

\begin{abstract}
The influence of the hot isostatic pressing (HIP) post-processing step on structural and phase changes, porosity healing and mechanical strength in a powder metallurgy Ti35Nb2Sn alloy was studied. Powders were pressed at room temperature at $750 \mathrm{MPa}$, and then sintered at $1,350^{\circ} \mathrm{C}$ in a vacuum for $3 \mathrm{~h}$. The standard HIP process at $1,200^{\circ} \mathrm{C}$ and $150 \mathrm{MPa}$ for $3 \mathrm{~h}$ was performed to study its effect on a Ti35Nb2Sn powder metallurgy alloy. The influence of the HIP process and cold rate on density, microstructure, the quantity of interstitial elements, mechanical strength and Young's modulus was investigated. HIP post-processing for $2 \mathrm{~h}$ at $1,200^{\circ} \mathrm{C}$ and $150 \mathrm{MPa}$ led to greater porosity reduction and a marked retention of the $\beta$ phase at room temperature. The slow cooling rate during the HIP process affected phase stability, with a large amount of $\alpha$ "-phase precipitate, which decreased the titanium alloy's yield strength.
\end{abstract}

Keywords: Hot isostatic pressing, $\beta$-Type titanium alloy, biomaterial, phase transformation, powder metallurgy

\section{Introduction}

The low elastic modulus of titanium alloys has replaced other metallic alloys, such as Co-Cr alloys and stainless steels (316L or 307), for load-bearing orthopaedic and dental implants [1]. The bone reabsorption issue is related to the stress shielding effect, which occurs due to a stiffness mismatch between implant and bone. Beta titanium alloys present the lowest Young's modulus by both enhancing the stress transmission between bone and the implant and inhibiting bone resorption [2,3].

The development of low-modulus high-strength beta titanium alloys is essential for the next generation of material prostheses to prolong implant lifetime beyond 15 years, which has been the standard for the past 50 years for Ti Cp and Ti6Al4V ELI alloys [4]. Mechanical properties are directly connected to their metallurgical processing routes, chemical composition and stabilised phases. The refractory elements added to stabilise the titanium beta phase $(\mathrm{Nb}, \mathrm{Mo}, \mathrm{Ta}, \mathrm{Zr})$ have a high melting point and a large difference in specific gravity, which seriously complicate the melting process, which requires 6-10 remelting steps followed by a homogenising annealing treatment to increase chemical and phase homogeneity [5,6]. The vacuum melting technologies (VIM, VAR, EBM) employed to obtain titanium alloys are complex and expensive, use considerable energy and often involve supplier delivery lead times of around 35 weeks [7].

Powder metallurgy (PM) technology is an alternative processing route to obtain beta titanium alloys, where the alloying elements used to stabilise the $\beta$ phase can be incorporated into the solid state during sintering. Conventional PM titanium alloys present a remaining porosity after sintering (2-8 vol\%) that can significantly reduce long-time performance. Therefore, the next advanced titanium alloys for the biomedical sector will rely on HIP post-processing to remove residual porosity, which will allow powder metallurgy to 
be processed by plastic deformation techniques [8-11]. HIP has been used for several decades in the aerospace and automotive industries to improve fatigue, ductility and fracture toughness [12]. Therefore, it is very important to predict materials' long-term behaviour to design and manufacture reliable implants. To avoid mechanical stress, corrosion and fatigue problems, titanium alloys must not present porosity, and must have excellent chemical homogeneity. Rapid cooling HIP furnaces enable the HIP cycle to be combined with conventional heat treatment where high cooling rates are required to stabilise the beta phase at room temperature. During a conventional HIP process, titanium powders need to be encapsulated in containers, degassed and sealed before the hot isostatic press cycle starts. However in the present study, the beta powder titanium samples were presintered under such conditions with residual porosity below $6 \%$ to allow the alloys to be hot isostatic-pressed directly without using containers.

The present paper proposes a processing route to obtain Ti35Nb2Sn based on conventional powder metallurgy (compact and sintering) and HIP post-processing. It aims to evaluate the effect of the HIP route on beta titanium powder metallurgy alloys (Ti35Nb2Sn) at different cooling rates.

\section{Materials and Methods}

\subsection{Processing conditions}

A new beta titanium alloy with a nominal Ti35Nb2Sn composition was fabricated by using a conventional powder metallurgical route (press and sintering). Hydride-dehydride titanium powder (99.7\%wt purity), niobium powder $(99.6 \% \mathrm{wt})$ and tin powder (99.6\%wt), with a maximum particle size particle of $45 \mu \mathrm{m}$, were chosen as the raw materials. Powders were weighed and prepared in an argon chamber GP Campus (Jacomax, Dagneux, France) to avoid oxidation. The mixture was prepared in a shaker mixer Turbula T2F (Willy A Bachofen AG, Muttenz Switzerland) for $2 \mathrm{~h}$ to increase homogeneity. Subsequently, rectangular samples $(30 \times 10 \times 10 \mathrm{~mm})$ were produced in a double-effect floating die press at $700 \mathrm{MPa}$ pressure. Green compacts were sintered in an HVT 15/75/450 tube vacuum sintering furnace (Carbolite Gero Ltd., Parson, UK) in a high vacuum at $<10-4$ mbars. Samples were heated to $800^{\circ} \mathrm{C}$ at $15^{\circ} \mathrm{C} / \mathrm{min}$, held at that temperature for $30 \mathrm{~min}$, heated to $1,350^{\circ} \mathrm{C}$ at $10^{\circ} \mathrm{C} / \mathrm{min}$, and finally held for $180 \mathrm{~min}$ and cooled at $10^{\circ} \mathrm{C} / \mathrm{min}$.

Without using containers, some sintered samples were hot isostatic-pressed under two different conditions. HIP was performed by a Quintus model QIH21 (Quintus Technologies $\mathrm{AB}$, Västerås, Sweden) under the following operation conditions: temperature of $1,200^{\circ} \mathrm{C}$, argon gas pressure of $150 \mathrm{MPa}$, holding time of $2 \mathrm{~h}$ and two different cooling rates: $500^{\circ} \mathrm{C} / \mathrm{min}$ and $100^{\circ} \mathrm{C} / \mathrm{min}$ (Fig. 1). Three scenarios (sintered, HIP1, HIP2) were designed to study the influence of the HIP process on the Ti35Nb2Sn alloys. The conditions for each experiment are found in Table 1.

Table 1. Parameters selected according to Ti35Nb2Sn processing step.

\begin{tabular}{lcccc}
\hline Processing route & Pressure (MPa) & $\begin{array}{c}\text { Maximum } \\
\text { Temperature }\left({ }^{\circ} \mathbf{C}\right)\end{array}$ & $\begin{array}{c}\text { Time } \\
(\text { minutes })\end{array}$ & $\begin{array}{c}\text { Cooling rate } \\
\left({ }^{\circ} \mathbf{C} / \text { min) }\right.\end{array}$ \\
\hline Vacuum Sintering & N/A & 1350 & 180 & 15 \\
HIP 1 (Fast cooling) & 150 & 1200 & 120 & 500 \\
HIP 2 (Slow cooling) & 150 & 1200 & 120 & 100 \\
\hline
\end{tabular}




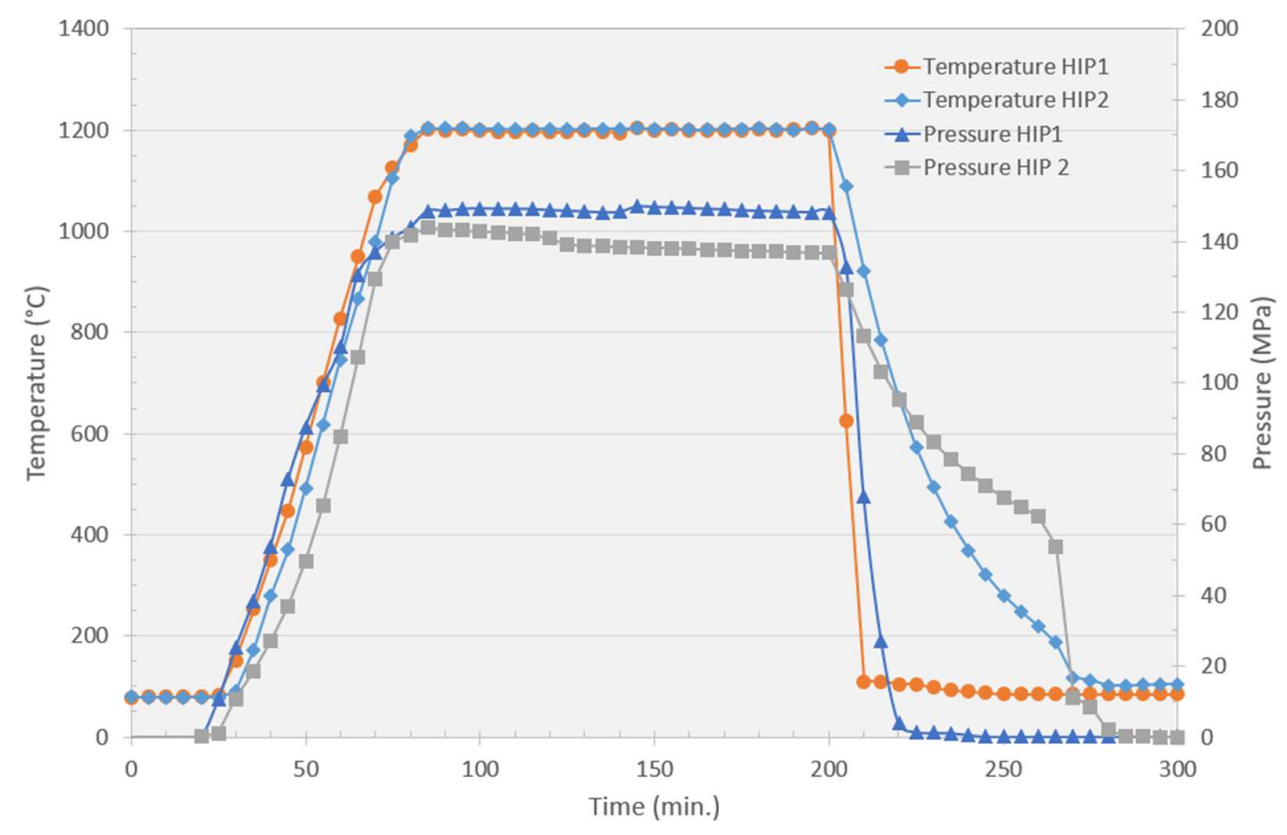

Figure 1. Temperature and pressure evolution during Hot Isostatic Pressing performed on Quintus QIH21 equipment.

\subsection{Characterization}

The relative density for each scenario was measured based on Archimedes' principle in accordance with ASTM standard C373-88. Tensile specimens were tested by a Shimadzu AG-X plus mechanical tester (Shimadzu, Kyoto, Japan) at a crosshead speed of 0.5 $\mathrm{mm} / \mathrm{min}$ following standard ISO 3325. The ultrasonic technique was selected to measure Young's modulus, for which the Sonelastic CA-DP equipment was employed (ATCP Ingeniería Física, Ribeirao Preto, Brazil).

The optical microscopy study (LV100 Nikon, Tokyo, Japan) was performed on the polished samples to observe internal residual porosity. To observe phases, present in Ti35Nb2Sn according to the processing route, the mechanically polished samples were etched in Kroll reagent to reveal their microstructure and to be viewed by optical microscopy. Grain size and orientation, morphology and phase distribution surface were characterised by a Scanning Electron Microscope (SEM, ZEISS, Oberkochen, Germany) and an Electron Backscatter Diffraction (EBSD) detector. The EBSD operated at $20 \mathrm{kV}$ and $5 \mathrm{nA}$, and step size was set at $0.05 \mu \mathrm{m}$ on a sample tilted $70^{\circ}$ from the horizontal for orientation mapping. The elemental analyses of the different processing routes were carried out by Energy Dispersive Spectroscopy (EDS) from Oxford Instruments Ltd. (Abingdon-onThames, UK).

\section{Results and Discussion}

The alloy's microstructure is one of the main factors controlling its tensile strength, wear resistance and corrosion resistance. Table 2 shows the variation in density, phases and average grains of the Ti35Nb2Sn alloy under different manufacturing conditions. Samples presented high densification, around $75 \%$ of the theoretical density after pressing, and approximately $98 \%$ after the sintering cycle, which was higher than $99 \%$ after HIP post-processing. As the percentage of the retained $\beta$ phase was above $20 \%$ at room temperature, the three processing conditions for Ti35Nb2Sn allowed classification in the $\beta$ titanium alloys category. 
Table 2. Archimedes' and metallographic characterization of the Ti35Nb2Sn alloy.

\begin{tabular}{cccccc}
\hline Processing route & $\begin{array}{c}\text { Green } \\
\text { density (\%) }\end{array}$ & $\begin{array}{c}\text { Relative } \\
\text { density (\%) }\end{array}$ & B phase (\%) & $\boldsymbol{\alpha}+\boldsymbol{\beta}$ phase (\%) & $\begin{array}{c}\text { Grain } \\
\text { size }(\boldsymbol{\mu m})\end{array}$ \\
\hline Vacuum Sintering & & $94,9 \pm 0,1$ & 38,4 & 56,5 & $19,1 \pm 11,3$ \\
HIP 1 (Fast cooling) & $80,2 \pm 0,5$ & $100,1 \pm 0,2$ & 95,5 & 3,7 & $57,2 \pm 32,3$ \\
HIP 2 (Slow cooling) & & $100,2 \pm 0,1$ & 78,9 & 20,8 & $55,2 \pm 33,5$ \\
\hline
\end{tabular}

The microstructures of the tested alloys are presented in Fig. 2. The $\alpha$-phase areas decreased with a rising HIP cooling rate. A heterogeneous phase composition was observed on the sintered and HIP 2 samples, composed predominantly by a $\beta$ equiaxial grain, with small areas with the $\alpha+\beta$ phase (Fig. 2A and 2C). As both temperature and pressure increased due to the HIP cycle, plastic deformation on the sintered samples took place. The HIP temperature above the beta transus temperature was required to reduce yield stress, and to enhance creep under pressure, to improve diffusion efficiency and remove residual porosity in a reasonable time (Table 2). The obtained data show that HIP post-processing gave relievable and repeatable results. The HIP process also significantly influenced the enlarged grain size. Initially for the sintered sample, the average grain size was around $19 \mu \mathrm{m}$ and then increased to $55 \mu \mathrm{m}$ after HIP post-processing increased (Table 2).
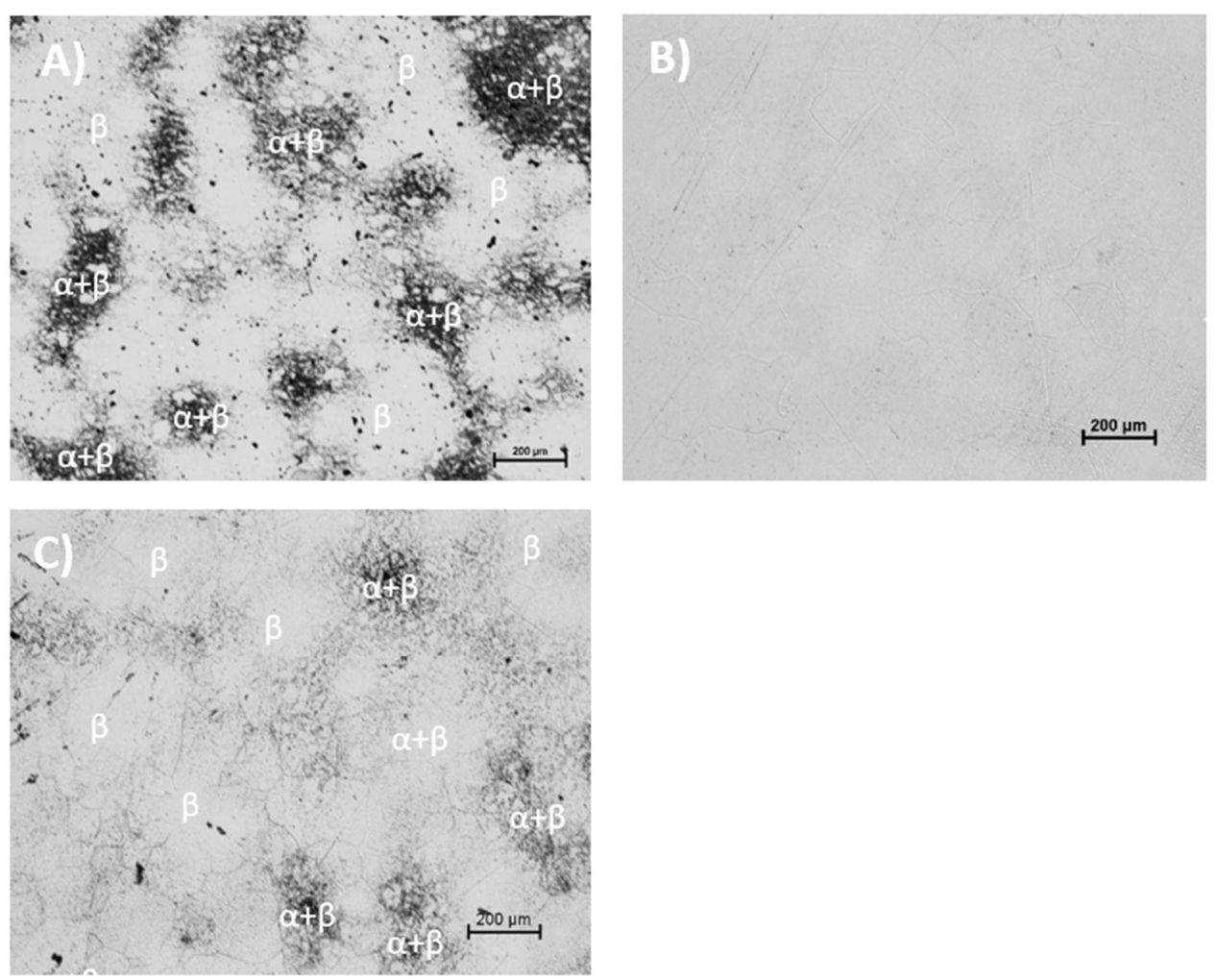

Figure 2. The microstructure of Ti35Nb2Sn according to its manufacturing condition. A) Conventional sintering at $1350{ }^{\circ} \mathrm{C}$ for 180 minutes. B) HIPed under $1200{ }^{\circ} \mathrm{C}, 150 \mathrm{MPa}$ and cooling rate 500 ${ }^{\circ} \mathrm{C} / \mathrm{min}$. C) HIPed under $1200{ }^{\circ} \mathrm{C}, 150 \mathrm{MPa}$ and cooling rate $100^{\circ} \mathrm{C} / \mathrm{min}$.

Nowadays, thermo-mechanical deformation metallurgical processes (forge, cold rolling, hot drawing) are employed to modify grain size, ductility and materials' tenacity 
$[13,14]$. This type of process cannot be performed on powder metallurgical material if residual porosity is higher than $2 \%$ because of the work hardening that materials present, which tends to fracture in the confirmation process. The present study corroborates that the inclusion of the HIP cycle after sintering on the beta titanium manufacturing route drastically reduced residual porosity, which allowed powder metallurgical titanium alloys to be submitted to the plastic deformation metallurgical process to obtain advanced titanium alloys. The mechanical-corrosion properties of titanium alloys depend on not only chemical and phase homogeneity, but also on morphology and grain size. This study shows that metastable $\beta$-type Ti35Nb2Sn alloys can be obtained when a $500^{\circ} \mathrm{C} / \mathrm{min}$ cooling rate is employed during HIP post-processing (Fig. 2B).

Figure 3 shows the Ti35Nb2Sn microstructures after performing HIP processing under different conditions from various scales by SEM and EBSD. The EBSD images demonstrated that the previous $\alpha+\beta$ areas detected by optical microscopy were actually $\alpha$ " precipitates at the $\beta$ matrix (Fig. 3B). The phases present at the microscopic level became more homogeneous, with no pronounced differences between the red ( $\beta$ phase) and yellow ( $\alpha^{\prime \prime}$ phase) areas after sintering and HIP processing. The EBSD analysis corroborated that the second HIP scenario, in which the titanium alloy was cooled more slowly from the $\beta$ field to room temperature at $100^{\circ} \mathrm{C} / \mathrm{min}$ instead of at $500^{\circ} \mathrm{C} / \mathrm{min}$, presented more intragranular $\alpha^{\prime \prime}$ precipitates around $32 \%$, compared with $5 \%$ quantified on the rapid cooling samples (HIP 1).
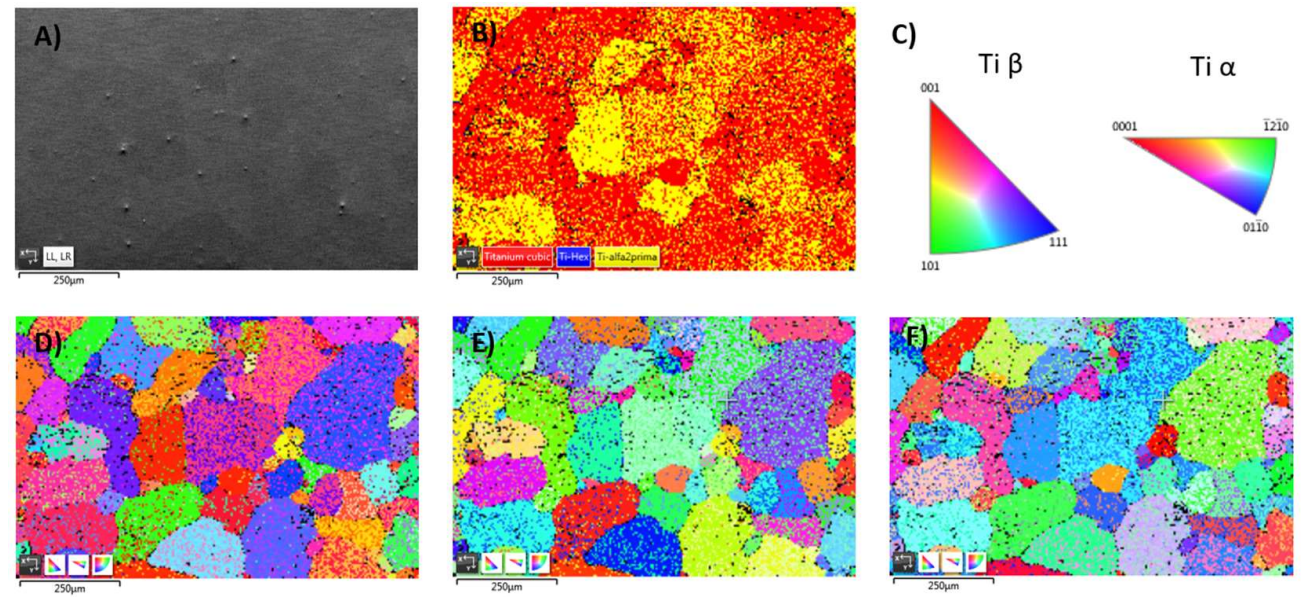

Figure 3. The microstructure of Ti35Nb2Sn after HIPping under $1200{ }^{\circ} \mathrm{C}, 150 \mathrm{MPa}$, and cooling rate $100{ }^{\circ} \mathrm{C} / \mathrm{min}$. A) SEM image. B) images showing the $\alpha^{\prime \prime}$ precipitates. D) Inverse pole figures (IPF) maps highlighting grains.

The SEM images and corresponding EDS mappings presented more significant information about alloying element distribution and diffusion on the titanium matrix. The microstructural analysis performed in EDS revealed that some parts were not completely homogeneous (Fig. 4C). These brighter areas presented low diffusion between niobium and the titanium matrix. The HIP cycle allowed the brighter areas to reduce due to the thermo-mechanical treatment, even though the titanium alloy's chemical homogeneity still had room for improvement.

The $\alpha+\beta$ regions with fewer refractory elements displayed high chemical heterogeneity. The mechanical characteristics obtained on the Ti35Nb2Sn alloy are summarized in Table 4 . The heterogeneity of the titanium phases $\left(\beta, \alpha\right.$, and $\left.\alpha^{\prime \prime}\right)$, together with residual porosity, were the main causes for the differences found in the titanium alloy's mechanical 
properties. Residual porosity reduction increased the percentage of ductility, and also improved Ti35Nb2Sn's mechanical response. The microstructure had a stronger influence on flexural strength rather than porosity, as reflected by flexural strength, which lowered from $900 \mathrm{MPa}$ to $700 \mathrm{MPa}$ when the $\alpha^{\prime \prime}$ content grew due to the $100{ }^{\circ} \mathrm{C} / \mathrm{min}$ cooling rate employed in HIP 2, even though porosity decreased in relation to the sintered sample (see Table 3).

Table 3. Mechanical results of the Ti35Nb2Sn alloy.

\begin{tabular}{cccccc}
\hline Processing route & UTS $\mathbf{( M P a )}$ & $\varepsilon(\%)$ & E (GPa) & G (GPa) & Poisson's ratio \\
\hline Vacuum Sintering & $993 \pm 82$ & $3,44 \pm 0,36$ & $70,49 \pm 1,09$ & $25,62 \pm 0,39$ & $0,38 \pm 0,04$ \\
HIP 1 (Fast cooling) & $997 \pm 63$ & $3,31 \pm 0,23$ & $71,23 \pm 2,04$ & $24,62 \pm 0,85$ & $0,45 \pm 0,06$ \\
HIP 2 (Slow cooling) & $702 \pm 80$ & $2,65 \pm 0,12$ & $72,29 \pm 1,04$ & $23,77 \pm 1,73$ & $0,53 \pm 0,13$ \\
\hline
\end{tabular}

Young's modulus is one of the most crucial mechanical properties to control the load transfer between the implant and bone [1, 2]. Given its low elastic modulus, excellent mechanical properties and greater corrosion resistance, TixNbySn is a promising candidate for medical use [3]. The large amount of beta stabilisers (niobium) in the alloy's composition contributed to lower Young's modulus, with values of $70 \mathrm{GPa}$, which improved the current 100 or $110 \mathrm{GPa}$ that today's titanium alloys employed in prosthesis present (Ti CP and Ti6Al4V ELI), and may minimise bone atrophy due to the stress shielding effect, which increases implant durability.

Li et al. (2011) found that Ti2448 alloys fabricated by powder metallurgy exhibited very limited ductility $(\sim 2 \%)$ during tensile tests. Their mechanical properties can be substantially improved simply by solution treatment at a suitable temperature, followed by water quenching. After heat treatment, Ti2448 elongation increased to $15 \%$ and it's Young's modulus lowered to $58.3 \mathrm{MPa}$ [15]. Severe plastic deformation fabrication methods draw a great of attention to the $\beta$-type biomedical alloys field as they add grain refinement, which significantly increases both strength and fatigue life expectancy [16-18]. Developing an appropriate microstructure with optimum mechanical properties and good corrosion resistance is a challenging problem in the low modulus $\beta$-type titanium alloys field, which should be addressed in the biomedical industrial sector. This would imply the inclusion of an advanced thermo-mechanical process, such as hot drawing and working or ECAP, heat and electrochemical treatments [19-22].

\section{Conclusions}

This study confirms that field-assisted consolidation processes, such as HIP, can be employed to reduce residual porosity and to increase the chemical and phase homogeneity of beta powder metallurgy titanium alloys. When applying $\mathrm{HIP}$ at $1,200^{\circ} \mathrm{C}$ and 150 $\mathrm{MPa}$ for $3 \mathrm{~h}$ to pre-sintered Ti35Nb2Sn samples, a high degree of densification occurs, which allows residual porosity to close and the density theoretical value to be obtained. As the cooling rate during the HIP process lowers from $500^{\circ} \mathrm{C} / \mathrm{min}$ to $100^{\circ} \mathrm{C} / \mathrm{min}$, the phase transformation from the $\beta$ phase (bcc) to the $\alpha$ phase (hcp) is restricted and the supersaturated $\alpha^{\prime \prime}$ phase appears, which diminishes Ti35Nb2Sn yield strength and elongation. 

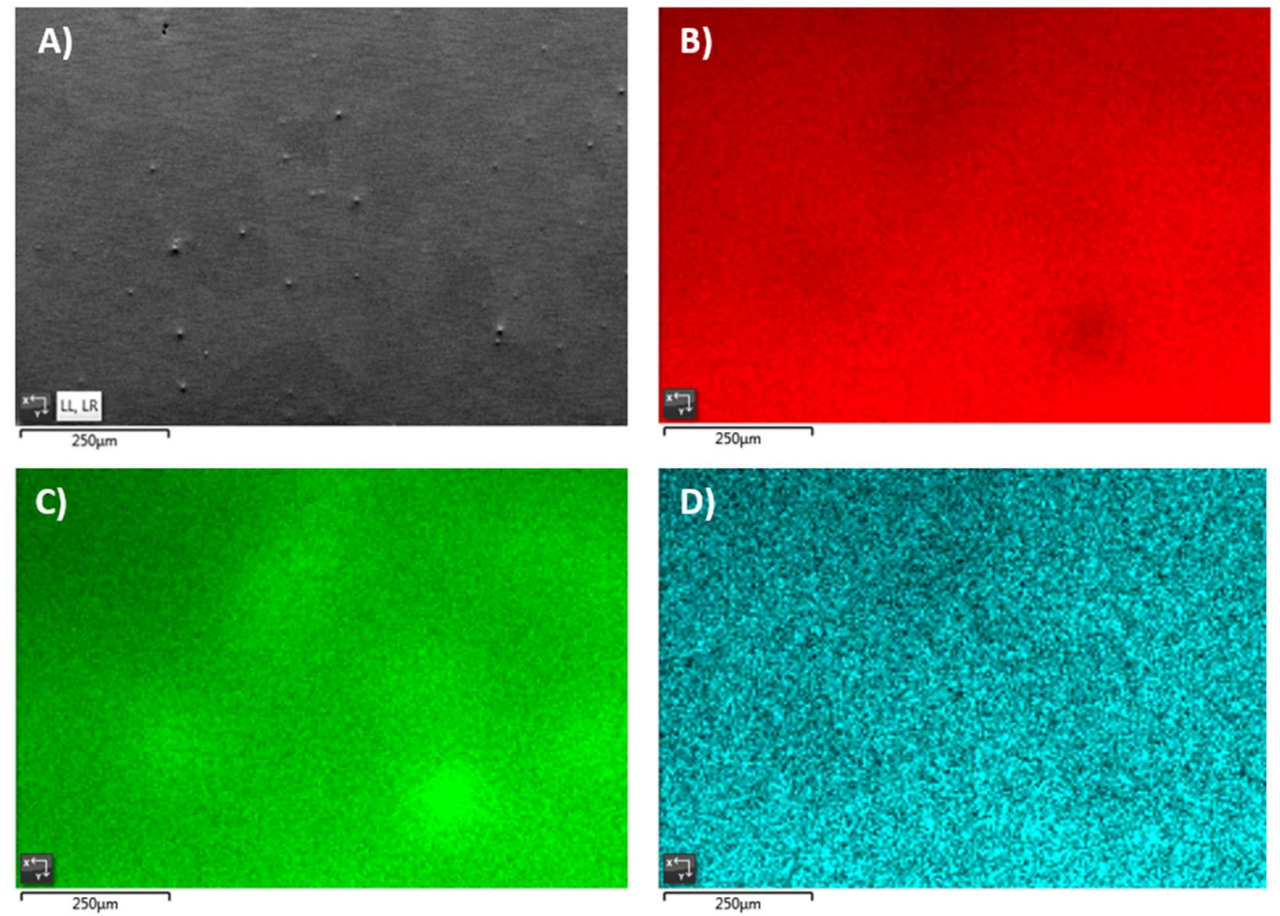

Figure 4. SEM and EDS mapping of $\mathrm{Ti}, \mathrm{Nb}$, and $\mathrm{Sn}$ respectively, for Ti35Nb2Sn HIPed at $1200{ }^{\circ} \mathrm{C}$, $150 \mathrm{MPa}$ and cooled at $100{ }^{\circ} \mathrm{C} / \mathrm{min}$. A) SEM image. B) Titanium EDS mapping. C) Niobium EDS mapping. D) Tin EDS mapping.

\section{Conclusions}

This section is not mandatory but can be added to the manuscript if the discussion is unusually long or complex.

Author Contributions: Joan Lario and Vicente Amigó carried out the experiment. Joan Lario wrote the manuscript with support from Vicente Amigó. The samples were fabricated Joan Lario and Angel Vicente. Angel Vicente and Vicente Amigó helped supervise the project. All authors provided critical feedback and helped shape the research, analysis and manuscript.

Funding: The authors wish to thank the Spanish Ministry of Economy and Competitiveness for the financial support of Research Project MAT2014-53764-C3-1-R, the Generalitat Valenciana for support through PROMETEO 2016/040, and the European Commission via FEDER funds to purchase equipment for research purposes and the Microscopy Service at the Valencia Polytechnic University.

Data Availability Statement: Data available in a publicly accessible repository. The data presented in this study are openly available in FigShare repository at 10.6084/m9.figshare.14444570 .

Acknowledgments: Thanks to Johannes Gårdstam and Mat Sjöstedt from Quintus Technologies $\mathrm{AB}$, Sweden for the technical assistance and the realization of the HIP process.

Conflicts of Interest: The authors declare no conflict of interest. The funders had no role in the design of the study; in the collection, analyses, or interpretation of data; in the writing of the manuscript, or in the decision to publish the results.

\section{References}

1. Kuroda, D., Niinomi, M., Morinaga, M., Kato, Y., \& Yashiro, T. (1998). Design and mechanical properties of new $\beta$ type titanium alloys for implant materials. Materials Science and Engineering A, 243(1-2), 244-249. https://doi.org/10.1016/s0921$\underline{\text { 5093(97)00808-3 }}$

2. Niinomi, M. (2008). Mechanical biocompatibilities of titanium alloys for biomedical applications. Journal of the Mechanical Behavior of Biomedical Materials, 1(1), 30-42. https://doi.org/10.1016/j.jmbbm.2007.07.001 
3. Miura, K., Yamada, N., Hanada, S., Jung, T. K., \& Itoi, E. (2011). The bone tissue compatibility of a new Ti-Nb-Sn alloy with a low Young's modulus. Acta Biomaterialia, 7(5), 2320-2326. https://doi.org/10.1016/j.actbio.2011.02.008

4. Bjursten, L. M., Rasmusson, L., Oh, S., Smith, G. C., Brammer, K. S., \& Jin, S. (2010). Titanium dioxide nanotubes enhance bone bonding in vivo. Journal of Biomedical Materials Research - Part A, 92(3), 1218-1224. https://doi.org/10.1002/jbm.a.32463

5. de Mello, M. G., Dainese, B. P., Caram, R., \& Cremasco, A. (2018). Influence of heating rate and aging temperature on omega and alpha phase precipitation in Ti-35Nb alloy. Materials Characterization, 145(March), $268-276$. https://doi.org/10.1016/j.matchar.2018.08.035

6. Málek, J., Hnilica, F., Veselý, J., \& Smola, B. (2013). Heat treatment and mechanical properties of powder metallurgy processed Ti-35.5Nb-5.7Ta beta-titanium alloy. Materials Characterization, 84, 225-231. https://doi.org/10.1016/j.matchar.2013.08.006

7. Cui, C., Hu, B. M., Zhao, L., \& Liu, S. (2011). Titanium alloy production technology, market prospects and industry development. Materials and Design, 32(3), 1684-1691. https://doi.org/10.1016/j.matdes.2010.09.011

8. Duan, W., Yin, Y., Zhou, J., Wang, M., Nan, H., \& Zhang, P. (2019). Dynamic research on Ti6Al4V powder HIP densification process based on intermittent experiments. Journal of Alloys and Compounds, 771, 489-497. https://doi.org/10.1016/j.jallcom.2018.08.261

9. Cao, L., Wu, X., Zhu, S., Mei, J., Wu, X., \& Bettles, C. (2014). The effect of HIPping pressure on phase transformations in Ti-5Al5Mo-5V-3Cr. Materials Science and Engineering A, 598, 207-216. https://doi.org/10.1016/j.msea.2014.01.013

10. Dekhtyar, A. I., Bondarchuk, V. I., Nevdacha, V. V., \& Kotko, A. V. (2020). The effect of microstructure on porosity healing mechanism of powder near- $\beta$ titanium alloys under hot isostatic pressing in $\alpha+\beta$-region: Ti-10V-2Fe-3Al. Materials Characterization, 165(April), 110393. https://doi.org/10.1016/j.matchar.2020.110393

11. Atkinson, H. V., \& Davies, S. (2000). Fundamental aspects of hot isostatic pressing: An overview. Metallurgical and Materials Transactions A: Physical Metallurgy and Materials Science, 31(12), 2981-3000. https://doi.org/10.1007/s11661-000-0078-2

12. Samarov, V., Seliverstov, D., \& Froes, F. H. (2015). Fabrication of near-net-shape cost-effective titanium components by use of prealloyed powders and hot isostatic pressing. In Titanium Powder Metallurgy: Science, Technology and Applications. Elsevier Inc. https://doi.org/10.1016/B978-0-12-800054-0.00018-6

13. Málek, J., Hnilica, F., Veselý, J., \& Smola, B. (2013). Heat treatment and mechanical properties of powder metallurgy processed Ti-35.5Nb-5.7Ta beta-titanium alloy. Materials Characterization, 84, 225-231. https://doi.org/10.1016/j.matchar.2013.08.006

14. Zherebtsov, S. V., Dyakonov, G. S., Salem, A. A., Malysheva, S. P., Salishchev, G. A., \& Semiatin, S. L. (2011). Evolution of grain and subgrain structure during cold rolling of commercial-purity titanium. Materials Science and Engineering A, 528(9), 34743479. https://doi.org/10.1016/j.msea.2011.01.039

15. Li, X., Zhou, Y., Ebel, T., Liu, L., Shen, X., \& Yu, P. (2020). The influence of heat treatment processing on microstructure and mechanical properties of $\mathrm{Ti}-24 \mathrm{Nb}-4 \mathrm{Zr}-8 \mathrm{Sn}$ alloy by powder metallurgy. Materialia, 13(March), 100803. https://doi.org/10.1016/j.mtla.2020.100803

16. Li, Z., Zheng, B., Wang, Y., Topping, T., Zhou, Y., Valiev, R. Z., Shan, A., \& Lavernia, E. J. (2014). Ultrafine-grained Ti-Nb-Ta$\mathrm{Zr}$ alloy produced by ECAP at room temperature. Journal of Materials Science, 49(19), 6656-6666. https://doi.org/10.1007/s10853-014-8337-6

17. Valiev, R. Z., Semenova, I. P., Latysh, V. V., Rack, H., Lowe, T. C., Petruzelka, J., Dluhos, L., Hrusak, D., \& Sochova, J. (2008). Nanostructured titanium for biomedical applications. Advanced Engineering Materials, 10(8), 8-11. https://doi.org/10.1002/adem.200800026

18. Langdon, T. G. (2008). Processing of ultrafine-grained materials using severe plastic deformation: Potential for achieving exceptional properties. Revista de Metalurgia (Madrid), 44(6), 556-564. https://doi.org/10.3989/revmetalm.0838

19. Amigó-Borrás, V., Lario-Femenía, J., Amigó-Mata, A., \& Vicente-Escuder, Á. (2020). Titanium, Titanium Alloys and Composites. Reference Module in Materials Science and Materials Engineering, 1(110). https://doi.org/10.1016/b978-0-12-819726-4.00044-2

20. Ahlfors, M., Hjärne, J., \& Shipley, J. (2018). Cost effective Hot Isostatic Pressing . A cost calculation study for AM parts . Quintus Technologies, (September), 1-6.

21. Torralba, J. M., \& Campos, M. (2014). Toward high performance in Powder Metallurgy. Revista de Metalurgia, 50(2). https://doi.org/10.3989/revmetalm.017

22. Lario-Femenía, J., Amigó-mata, A., Vicente-escuder, Á., \& Segovia-lópez, F. (2016). Desarrollo de las aleaciones de titanio y tratamientos superficiales para incrementar la vida útil de los implantes. Revista de Metalurgia, 52(4), 1-13. https://doi.org/http://dx.doi.org/10.3989/revmetalm.084 